\title{
Sujetos colectivos en búsqueda de sustentabilidad pesquera: relatos de los miembros de una comunidad de pescadores artesanales, V región, Chile*
}

\author{
Violeta Glaría
}

Universidad Valparaíso, Valparaíso, Chile. Email: violetaglaria@socioeconomia-uv.cl

\begin{abstract}
Resumen: A nivel nacional e internacional los desembarques de pesca se han incrementado cuantiosamente en los últimos decenios generando el colapso de diversas pesquerías. Los testimonios de los miembros de la comunidad de pescadores artesanales de la V región son uno de los ejemplos concretos de este proceso. Se argumentó que estas crisis eran provocadas por la "Tragedia de los Comunes” y que era necesario establecer Cuotas Individuales Transferibles (CIT) para asegurar los derechos de propiedad. La versión nacional, con la ley 19.713, estableció la privatización del acceso a la pesca con los Límites Máximos de Captura por Armador (LMCA), para el sector industrial, y, posteriormente, con la ley 19.849, los Regímenes Artesanales de Extracción (RAE), para el sector artesanal. El 2012 vencen estas leyes y los pescadores artesanales deberían tener un rol significativo en la determinación de la nueva administración pesquera, por cuanto ellos, al depender de los ecosistemas marinos para su subsistencia, tienen genuino interés en la sustentablidad del manejo pesquero.
\end{abstract}

Palabras clave: Pesca artesanal, sustentabilidad, ley de pesca, cuotas individuales transferibles.

\section{Colective subjects in the search of fishing sustainability: histories of a traditional fisherman's community, $\mathrm{V}$ region, Chile}

\begin{abstract}
At international and local level the fishing captures have been enormously increased during the last decades, generating the collapse of several fisheries. The traditional fishermen's community testimonies in the Chilean $5^{\text {th }}$ region, are concrete examples of this process. It was argued that these crises were caused by the "Tragedy of the Commons" and that it was necessary to establish Individual Tranferable Quota (CIT) to secure the ownership rights. The national version with the $19.713 \mathrm{Law}$, was the privatization of the fishing activity access by a "Maximum Capture Limit by Owner” (Límite Máximo de captura por Armador, LMCA) to the industrial sector and later, with the law 19.849, the "Artisanal Extraction Regime” (Régimen Artesanal de Extracción, RAE) to the traditional one. The mentioned laws expires in 2012 and the traditional fishermen should have a significant role in determining the new fishing management. Depending their subsistence on the marine ecosystems, they have true interest in the
\end{abstract}


sustainability of fishing control.

Key words: Traditional fishermen, sustainability, fishing law, individual transfer quota.

\title{
Os atores coletivos em busca de uma pesca sustentável: histórias de membros de uma comunidade de pescadores, V Região do Chile
}

\begin{abstract}
Resumo: A desembarques nacionais e internacionais têm aumentado muito nas últimas décadas, gerando o colapso de várias pescarias. Os depoimentos dos membros da comunidade de pescadores da região V é um dos exemplos específicos deste processo. Foi alegado que essas crises foram causadas pela "Tragédia dos Comuns” e à necessidade de estabelecer quotas individuais transferíveis (CIT) para proteger direitos de propriedade. A versão nacional, com lei 19.713 estabeleceu a privatização do acesso à pesca com os limites máximos de captura por Proprietário (TCE), para o setor industrial e, posteriormente, com a lei 19.849, Mineração Artesanal Regimes (RAE ) para o setor artesanal. Estas leis expiram em 2012 eos pescadores artesanais deveriam ter um papel significativo na determinação da nova gestão da pesca, pois, dependem de ecossistemas marinhos para a sua subsistência e têm genuíno interesse em a sustentablidade na gestão das pescas.
\end{abstract}

Palavras-chave: pesca artesanal, sustentabilidade, lei da pesca, quotas individuais transferíveis

$* * *$

\section{Introducción}

"La pesca del bacalao, del arenque y otros son inacabables, quiero decir que nada de lo que hagamos seriamente afectará el número de peces.”

T. H. Huxley en $1833^{1}$

Durante muchos años se pensó que los mares eran una ilimitada fuente de recursos y que no importaba cuantas personas explotasen los ecosistemas marinos ni cuanto extrajeran de los mismos. En coherencia con esta comprensión los niveles de desembarque de captura se incrementaron sostenidamente en el tiempo. En la década de los 50`s la pesca mundial de captura se encontraba alrededor de las 20 millones de toneladas, cuadro décadas después este valor se había multiplicado por cuatro $^{2}$ (FAO, 2009).

Este incremento sostenido de los esfuerzos pesqueros a nivel mundial ha generado el deterioro paulatino de múltiples pesquerías, el 28\% de ellas se encuentran actualmente sobreexplotadas, agotadas o en fase de recuperación, el 52\% en el límite máximo de explotación y que apenas un $20 \%$ de las especies se encuentran infraexplotadas o moderadamente explotadas (FAO, 2009). Este deterioro ecosistémico ha traído como conse- 
cuencias múltiples crisis para los pescadores artesanales en diversos lugares del mundo debido al ineludible vínculo que este sector tiene a la productividad de los ecosistemas marinos. (Cruz y Argüello, 2006).

Desde la economía neoclásica Hardin planteó que la situación de sobreexplotación de diversos recursos naturales se debía a la "Tragedia de los Comunes” (Hardin, 1968), donde todo recurso sometido al libre acceso se encontraba irremediablemente condenado al deterioro ya que, en forma individual, no existía incentivo para cuidar lo que se encontraba libremente disponible, según esta lógica la solución liberal pasa por demarcar claros derechos de propiedad de los recursos para que puedan existir negociaciones entre los sujetos involucrados (Coase, 1960). La hipótesis es que en la medida en que estos bienes comunes se vuelven privados existe alguien que tiene interés en cuidarlos porque le pertenecen y que las leyes del mercado van a tender a una situación de máxima eficiencia (Yu Chang, 2005).

Siguiendo esta lógica a nivel internacional se incentivó la privatización del acceso a la pesca por lo que los derechos de pesca tendieron a transformarse en derechos de propiedad privada comercializables, generando dinámicas de marginación y barreras de acceso a los más débiles (Ben- Yami, 2003). Se promovió la implementación de cuotas globales de pesca, el fraccionamiento de éstas en Cuotas Individuales Transferibles (CIT o ITQ ${ }^{3}$ ) y su regulación a través de las leyes del mercado (Copes; 1999).

A nivel nacional los niveles de extracción pasaron de ser inferiores a 1 millón de toneladas hasta la década del 60 a multiplicarse por ocho en las cuatro décadas siguientes, llegando en 1994 al máximo de extracción conocido con 8,02 millones de toneladas, esto generó una merma considerable de los desembarques en los años siguientes llegando, en 1998, a 3,8 millones de toneladas para aumentar posteriormente y mantenerse alrededor de las 4, 5 millones de toneladas anuales (Dirección de Pesca y Caza 1944-1973, División de Protección Pesquera, 1974-1976 y Servicio Nacional de Pesca 1979-2009). Estos aumentos en la presión extractiva llevaron al colapso de importantes pesquerías nacionales, la sardina española en el norte, el jurel en la zona centro sur, la merluza común en la zona central, entre otras.

Las CIT, en nuestro país, tomaron el nombre de Límites Máximos de Captura por Armador (LMCA) para el sector industrial y Registros Artesanales de Extracción (RAE) para el sector artesanal y se implementaron el año 2001, con la ley 19.713 y el año 2002, con la ley 19.849, respectivamente.

La crisis de la merluza en la V región llevó al stock de biomasa de merluza común en el año 2004 al 18\% del estimado en el 2002 (CONAPACH, 2007), lo que resultó un golpe fatal para el sector artesanal regional ya que la región de Valparaíso se había especializado en la extracción de dicha especie. 
Ante esta crisis los pescadores artesanales decidieron movilizarse masivamente en la región. En estas protestas, que incluyeron un bote en llamas adentrándose en el Congreso Nacional, cortes de calles y peleas con carabineros a "remazo limpio", los pescadores artesanales denunciaban la crisis de la merluza común, su desacuerdo con la Ley de Pesca, la necesidad de prohibir el arrastre industrial, la falta de poder de decisión de los pescadores artesanales, la injusta repartición de las cuotas de pesca y su repudio a la privatización del acceso a las cuotas de pesca.

El 31 de diciembre del año 2012 termina la ley 19.713 al vencer la ley 19.849 que la prorrogó. Caduca la legalidad que privatizó el acceso de pesca en el país por lo que el debate ya ha comenzado y los distintos actores hacen sus propuestas y buscan el mejor argumento que defienda sus intereses, ¿seguirá el sistema de LMCA y los RAE?, ¿cuáles son las mejores medidas administrativas a implementar a través de la nueva legalidad? ¿cómo se repartirán las cuotas de pesca, por criterios históricos, como se ha hecho hasta este momento, o por subasta? ¿qué porcentaje irá al sector industrial y al sector artesanal?.

En este escenario la participación real y efectiva del sector artesanal (además de la sociedad civil y la comunidad científica), resulta indispensable para asegurar la sustentabilidad del manejo pesquero y la soberanía alimentaria del país. Si este debate es definido por el lobby de los grandes grupos de interés pesquero industrial peligra con prevalecer la maximización de utilidades del hoy por sobre la sanidad de los ecosistemas marinos del mañana.

\section{Antecedentes Legales Nacionales}

“El mar será el petróleo del futuro y para Chile será inagotable”

Almirante Merino ${ }^{4}$

Con la dictadura militar comienza a constituirse la institucionalidad y legalidad pesquera vigente: se crea la Subsecretaría de Pesca (SUBPESCA) y el Servicio Nacional de Pesca (SERNAPESCA), a través del D.L. $\mathrm{N}^{\circ}$ 1.62 (1976) y D.L. $\mathrm{N}^{\circ} 2.442$ (1978) respectivamente, concebidos como entidades dependientes del Ministerio de Economía, Fomento y Reconstrucción (hasta ese entonces los entes reguladores de la pesca, la Dirección de Pesca y Caza, primero, y la División de Protección Pesquera, después, dependían del Ministerio de Agricultura). En 1980 la nueva constitución del país establece que los recursos marinos vivos son "res nullius" (territorio de nadie) abriendo el acceso a las pesquerías nacionales (Quiroga; Van, 1994).

En 1989, el ejecutivo propuso la ley 18.892, Ley General de Pesca y Acuicultura (LGPA), la que fue aprobada (luego de diversas modificaciones) en 1991 (Quiroga y Van, 1994). La LGPA trajo consigo importantes 
cambios como el fin de la Libertad de Pesca en las pesquerías diagnosticadas como "sobreexplotadas", la asignación de cuotas globales de pesca inapelables a través del Consejo Nacional de Pesca (CNP) (instancia donde encuentran representados los distintos sectores pesqueros que recibe una recomendación de cuota de la SUBPESCA que a su vez recibe una recomendación de cuota del IFOP, encargados del análisis científico), la creación de los Registro Nacional de Pescadores Artesanales (RNPA) (donde se restringe el movimiento regional del sector artesanal) y el establecimiento de Áreas de Manejo (parcelación del sector costero). A través de esta ley el Estado se reservó el derecho de restringir las tallas de captura y las características de algunas de las técnicas de pesca, además de decretar las vedas que se diagnostiquen pertinentes (SUBPESCA, 2007).

La LGPA establece a la pesca artesanal como una: "actividad pesquera extractiva realizada por personas naturales que en forma personal, directa y habitual trabajan como pescadores artesanales.” (LGPA), en esta definición se omiten las características culturales de este oficio (la pesca artesanal es más que una actividad extractiva es una expresión cultural).

Se crea la figura legal de Armador Artesanal definido como el "pescador artesanal a cuyo nombre se explotan hasta dos embarcaciones artesanales" (LGPA). Y la embarcación es definida como: "Embarcación explotada por un armador artesanal, de una eslora máxima no superior a dieciocho metros y de hasta cincuenta toneladas de registro grueso, identificada e inscrita como tal en los registros a cargo de la autoridad marítima” (LGPA). De esta forma el armador es quien explota una embarcación artesanal. Esta definición traerá profundas consecuencias con la implementación de los RAE el 2002 ya que las cuotas de pesca le serán asignadas al armador en desmedro de los pescadores que carecen de embarcaciones de pesca.

Por otro lado, dada la definición de embarcación artesanal en la LGPA, no hay criterio que permita excluir a aquellas naves equipadas con adelantos tecnológicos que superan ampliamente la capacidad de captura de los pescadores artesanales tradicionales y que pueden pescar en las 5 millas de "preferencia" artesanal. Con esta definición se homogenizan tres tipos de pesca artesanal bien diferenciadas que tienen características propias, la pesca artesanal avanzada o semi-industrial, la pesca artesanal tradicional y la pesca de subsistencia (FAO, 2000).

Durante el año 2001 se aprobó una ley transitoria, de dos años de duración: la ley 19.713 (D.O. 25/01/2001) con la que se establecieron los Límites Máximos de Captura por Armador (LMCA) para el sector industrial, posteriormente esta ley fue prorrogada hasta el año 2012 con la ley 19.849 (D.O. 26/12/2002). Los LMCA se aplicaron en todas las pesquerías en estado de plena explotación que estaban sujetas a una cuota global anual. Las cuotas globales fueron divididas por criterios de desembarque histórico, es decir, aquel que extraía más tenía derecho a tener un mayor 
porcentaje de la cuota global. Las cuotas adquirieron valor monetario que fue entregado gratuitamente por el Estado. Se privatizó el acceso a la pesca en el país y se le otorgó la mayor parte de las cuotas globales, en promedio el 80\%, al sector industrial. (CONAPACH, 2006).

Con la ley $19.849^{5}$ se comenzaron a implementar los Regímenes Artesanales de Extracción (RAE). Se aplicó la lógica de las CIT al sector artesanal dividiendo la cuota global entregada al sector artesanal en cuotas individuales asignadas a cada uno de los armadores artesanales. Esta medida generó rechazo en el sector artesanal logrando algunas negociaciones favorables como la implementación de un Bolsón, una gran cuota común, para las caletas que no quisiera adherir a este sistema.

El 12 de junio de 2002 ingresó al Senado el Proyecto de Ley conocido como "Ley Larga”, que aún no ha sido aprobado dadas las reticencias que despierta al pretender mantener de forma permanente los LMCA como medida de administración pesquera.

El 31 de Diciembre del 2012, caducará la ley 19.713 (al terminar la ley 19.849), por lo que ya ha comenzado la discusión en torno a la nueva reglamentación que se implementará. Los intereses involucrados son poderosos, tanto nacionales como transnacionales, lo que está en juego es la sustentabilidad del manejo pesquero nacional, y con él, el futuro de las comunidades de pescadores artesanales y una parte importante de la soberanía alimentaria del país.

\section{Relatos de una comunidad de pescadores artesanales}

Para comprender lo que ha pasado con los ecosistemas marinos resulta esencial conocer la versión de aquellos que los han vivenciado y conocido desde la niñez. Es en este sentido que el relato de los miembros de la comunidad de pescadores artesanales resulta una aporte valioso al análisis de la situación actual y las perspectivas futuras. Al preguntarles acerca de cómo era "la mar" en el pasado surgen imágenes de una gran biodiversidad y abundancia de la pesca.

"Hace 30 años , más o menos, acá en la zona de Valparaíso, en la zona central, nosotros teníamos una diversidad de pesca, (...) teníamos la albacora, el atún, la corvina, el congrio, la sierra, el jurel de tamaño, una diversidad de pesca enorme, la cadena trófica acá se daba” Pescador y Dirigente, 62 años ${ }^{6}$

Esta diversidad de pesca tenía una serie de implicancias en términos productivos, se pescaba por temporada, en ciertos horarios del día según la especie objetivo, se podía escoger a qué pesca ir cada día y con técnicas de pesca muy rudimentarias se lograba gran efectividad.

"Pillábamos atunes con artes de pesca muy precarios: corontas de 
choclo les colocábamos pedillo, no llegaba el plástico (...) Trabajábamos con lienza, era rústico (...) todavía era cáñamo.” Pescador y Ex Dirigente, 63 años.

Estos métodos artesanales de pesca generaban trabajo para muchas personas en la caleta, había que hacer los botes, tirarlos al mar devolverlos a tierra, repararlos, había que hacer las redes, los espineles, encarnarlos, tenderlos, etc. por esto se requería de una gran número de personas en el trabajo de la caleta.

"No existía la tecnología que va cortando brazos, por ser... habían tiradores de botes, lavadores de botes (...) habían maestros que trabajaban, arreglaban los botes, carpintero de ribera que le llamaban (..) Habían encarnadoras, ahora eso no se ve tampoco, porque todo cambio” Buzo y Pescador, 56 años.

El trabajo de las caletas se sustentaba en base a vínculos familiares y amistosos, se formaban comunidades de pescadores artesanales, con su propios códigos, costumbres e identidad. La historias familiares de tejían en torno al trabajo de la caleta sus ritmos, características y requerimientos, generando un colectivo humano con una idiosincracia propia.

"Las familias antes eran más allegadas aquí, pasamos el año nuevo casi todas las familias de los pescadores juntas (..) Todos entrábamos en la casa de uno y después a la casa del otro (...) los pescadores vivían casi todos en el sector (...) Hacíamos fiestas nosotros, aquí antiguamente, el club deportivo con el sindicato eran una sola cosa (...) hacíamos paseos toda la caleta”. Dirigente, 62 años.

Los oficios de la pesca artesanal se traspasaban de generación en generación en la práctica cotidiana de las caletas. La familia era la encargada de enseñar el arte de la pesca artesanal.

"Yo soy nacido y criado en esta caleta, mi gente de atrás son mis abuelos, mis bisabuelos y yo... y ahora viene mi hijo, que a veces va a trabajar conmigo « Pescador, 30 años.

En las familias de los pescadores artesanales cada miembros tenía un rol, las mujeres tejían las redes y encarnaban, los hombres hacían los botes y salían a la mar, los niños ayudaban a los adultos. Dado que el trabajo era familiar, los niños se criaban en torno a la pesca y se constituían identitariamente como pescadores artesanales, ser pescador no es sólo un trabajo es una cultura, una forma de vida.

"Yo pescaba los espineles (...) llegaba a la casa, mi vieja con mis hermanas lo tendían y encarnaban. Se hacia todo en las casas en ese tiempo (...) había que hacer la red entera (...) las mamás, las hermanas, todas sabían tejer, las familias de los pescadores antes todas sabían tejer, porque se amanecían tejiendo, para poder hacer los paños 
pa' la pesca que eran de hilo” Pescador, 69 años.

Con el correr de los años fueron desapareciendo las especies que daban sustento a los pescadores, la inmensa biodiversidad que caracterizaba la costa de la zona central fue mermando paulatinamente. Dada la escasez de otras especies los pescadores se especializaron en la merluza común, se dejó de pescar por temporadas de acuerdo a los ciclos de las distintas especies.

"La sierra y el jurel, esas dos especies que pa' nosotros eran sustentables en verano, ya no estaban, entonces ¿qué pasa? se optó por seguir con la merluza, para nosotros la merluza no estaba en invierno, nos íbamos a otras pescas, y la merluza quedaba ahí y fue ese el cambio que las otras pecas van desapareciendo. Y tuvimos que seguir buscando merluza, hasta que abre el año la merluza, ya no hay meses pa' la merluza, meses pa' esto pa' lo otro.... merluza todo el año... y lo que va quedando!!” Pescador, 60 años.

En diversas caletas, dada la escasez de sardina para encarnar y el alto costo del espinel, por la cantidad de trabajo que involucra, se optó por cambiar la técnica de pesca utilizada, pasando del espinel al enmalle.

“Ahora no hay ni sardina, no se puede ir al espinel (...) es mucho el volumen que tienen en el norte y el sur

pa' la harina, cuando la harina es el peor desperdicio que hay” Pescador, 60 años.

Con este cambio en los aparejos de pesca utilizados, las encarnadoras, usualmente parejas de los pescadores, quedaron cesantes y tuvieron que salir a buscar trabajo afuera de la caleta, con lo que se perjudicó el núcleo de transmisión esencial de la pesca artesanal: la familia.

"Era muy atractivo que la mujer de uno se dedicara a encarnar para que fuera partícipe de las actividades del hombre (...) ahora por ejemplo ya no se usan encarnadoras, con las redes se perdió la labor de las encarnadoras ¡a la borda la encarnadora!.” Pescador, 80 años

Cuando la merluza común entró en crisis los pescadores artesanales se vieron sumidos en la pobreza extrema lo que los llevó a iniciar diversas movilizaciones en la región.

"Ahora nos tenemos que andar peleando para que nos quede un poco (...) miren ahora, poca merluza, ahí están los cabros, todos traen poquitas, 10 docenas, 5 docenas, ¡nada! (...) la merluza ya está en exterminación”. Dirigente, 62 años.

Ante estas circunstancias el traspaso generacional del oficio de la pesca artesanal se ha mermado mucho, los pescadores han dejado de llevar a sus hijos al mar al considerarlo un error. 
"Yo creo que la generación llega hasta aquí porque es difícil que sigan las nuevas generaciones, ya que muchos hijos de los pescadores han migrado de aquí, debido, justamente, a la crisis que se formó (...) El pescador si tiene hijos, comete un error al llevarlos a la mar, porque se entusiasman, ¡les gusta la vida en la mar! ¡les gusta!.” Pescador, 80 años.

Oficialmente se ha dicho que la crisis de la merluza se debe a la invasión de la jibia que ha depredado los recursos marinos, los pescadores artesanales reconocen la importancia de este fenómeno, la jibia es, efectivamente, muy voraz, sin embargo, no es la raíz del problema.

"Esta situación de escasez de recursos que el Estado quiere justificar con la gran invasión de jibia... ¿¿¿¿̇a dónde???, nosotros decimos. Puede ser parte causante pero no es, en general, el causante, porque la jibia siempre ha estado en los mismo volúmenes, con la única diferencia que antes existía una cadena trófica que hacía de muralla a ese gran volumen de jibia, porque antes de entrar a la costa se enfrentaban al tiburón, la albacora, la ballena, los recursos naturales que se depredan entre ellos, al no existir esa cadena trófica cualquier especie entra en banda' pa' adentro” Pescador y Dirigente, 62 años.

La raíz del problema se encuentra en la industrialización y el aumento excesivo en las capturas que se logra a través de estos medios.

"Empezó a crecer la industrialización de las capturas y empezaron a bajar las especies, en este momento, la única especie que mantenemos para el sustento es la merluza común” Pescador y Dirigente, 62 años.

Los pescadores sienten que los principales responsables de la degradación marina son los grandes barcos industriales.

“Aquí llegan los barcos del norte... del sur, son tremendo barcos (...) son barcos fábrica, son toneladas las que pillan (...) y es un crimen pillar tanto...” Pescador, 56 años.

En particular responsabilizan a las técnicas de pesca poco selectivas y altamente nocivas para los ecosistemas marinos como el arrastre de fondo.

"El peor enemigo del pecador artesanal es la pesca de arrastre (...) el arrastre mata todo, y los pescaditos chicos los botan (...) ni pa' harina les sirve” Pescador, 80 años.

Otra práctica relevante en la degradación de los ecosistemas marinos es el descarte, los grandes barcos industriales botan por la borda, muertos o agonizantes y sin posibilidad de recuperarse, a miles de pescados juveniles que se encuentran bajo la talla de extracción. 
"Si se imaginaran lo que significa el descarte de los grandes cerqueros y arrastreros, i¡se mueren 3 veces resucitan y se mueren de nuevo!!. Botan al mar un pescado vivo que está bajo la talla, que está prohibido venderse (...) y ese es el más grande crimen que se le puede hacer a la naturaleza. Ese pescadito se bota al mar y se lo comen los pájaros, se oxigenó, ya no puede agarrar profundidad. Cientos de miles de pescaditos que están muriendo” Pescador, 80 años.

En las caletas prima un sentimiento de depresión, de falta de esperanza, “pescadores al borde de la extinción” decía uno de los carteles de protesta de la caleta El Membrillo que denunciaba la profunda crisis en la que estaban inmersos. Sienten que, a pesar de todos los esfuerzos y todas las luchas, resulta difícil tener resultados positivos, ya que el daño ecosistémico es muy grande y la correlación de fuerzas desfavorables.

"Yo pienso que a nosotros nos van a borrar del mapa con el tiempo (...) soy sincero y pienso yo que pal gobierno somos un estorbo (...) hay que ser franco, los políticos ¿a quién le van a dar bola? ¿quién produce para el país?, los industriales po (...) ese es el que paga impuestos (...) ellos son los que le hacen entrar moneditas al país” Buzo y Pescador, 56 años.

La evolución de la legalidad pesquera ha implicado profundos cambios en sus formas de vida, con los Registros Nacionales de Pescadores Artesanales (RNPA), se les prohibió salir de sus caletas en busca de pesca en tiempos de escasez con lo que se agudizaron los efectos económicos de cualquier crisis pesquera, también repercutió en su concepción identitaria ya que los pescadores dejaron de ser "libres".

“Antes éramos libres, navegamos pa' donde queríamos, ahora nos tienen amarrados (...) se parcelaron los mares” Pescador y Ex Dirigente, 80 años

Con la asignación de las cuotas individuales de los RAE que le asignaron las cuotas al "armador” (dueño de la embarcación) y no al "pescador” (sin una embarcación) se atentó contra la estructura organizacional tradicional de la pesca artesanal, la Sociedad a la Parte, en la que las ganancias y pérdidas se comparten en parte iguales entre todos los participantes de la pesca, sin importar quien sea dueño de los materiales de pesca.

"A nosotros nos metieron la contradicción de clases en un bote de 8 metros” Pescador y Dirigente, 65

De momento varias de las caletas de la $\mathrm{V}$ región han logrado resistirse a este proceso a través del "Bolsón”, cuota general para diversas caletas administrada por los sindicatos no por los armadores particulares, de esta forma han logrado mantener cierto acceso colectivo a 
los recursos marinos.

"Se inventó para las caletas que no querían ese sistema, se hizo un bolsón que le llaman, y esas caletas tienen cuota global, entonces las caletas pescan y van sacando de ese bolsón” Pescador y Dirigente, 65 años.

Plantean que la actual legislación se hizo pensando en los intereses del sector industrial, sin contemplar las necesidades del sector artesanal ni la sustentabilidad de los ecosistemas marinos.

"Se le dio y se le dio a los industriales, porque lo único que se miró fue la cosa comercial (...) más defendieron el bolsillo de los empresarios que la parte social de los pescadores artesanales ii y eso es una realidad!!” Pescador y Dirigente, 62 años

Sienten que no pueden contrarrestar el poder de las grandes empresas pesqueras, sus influyentes directorios y accionistas, los que están depredando la pesca a lo largo de todo el país.

"Legislan para ellos, imagina los Zaldívar son dueños, amos y señores (...) La pesca industrial es la que ha matado a la pesca alrededor de todo Chile.... Y la sigue matando, no hay caso, no la para nadie” Pescador, 82 años.

Toda esperanza en lo que respecta al futuro de las pesca artesanal queda supeditada a un cambio de actitud y de concepción de la administración pesquera vigente. Las medidas a tomar son claras y urgentes, restringir los aparejos de pesca más nocivos y resguardar ciertas áreas de relevancia biológica, única forma de poder imaginar la recuperación de la merluza y de las otras especies.

"Hay zonas fundamentales que hay que proteger, la zona de desovadero, la zona de reclutamiento, las praderas naturales” Pescador y Dirigente, 62 años

El futuro de la pesca artesanal es incierto y los miembros de la comunidad de pescadores lo saben, las caletas lucen tristes y su gente empobrecida.

“¿esta wuea' cuándo va a tener futuro?” Encarnadora, 55 años.

Los viejos no tienen donde ir, no saben hacer otra cosa que pescar, las caletas envejecen junto a sus pescadores. Los más jóvenes quisieran continuar con el oficios de sus padres que conocieron desde niños, pero las necesidades de vida los obliga a tomar otros senderos.

"El futuro de la pesca artesanal es igual para todos malo, muy malo" Pescador (Ex Dirigente), 82 años. 


\section{La comunidad de pescadores artesanales como actores relevantes de la búsqueda de sustentabilidad pesquera}

La comunidad de pescadores artesanales tiene un profundo interés en la sustentabilidad del manejo de las pesquerías ya que su forma de vida, sus códigos, su cultura, su identidad se fundamenta en la pesca, por lo que no puede existir sin peces. En esta búsqueda de sustentabilidad la comunidad general también se beneficia.

"Nosotros queremos conservar los recursos para el futuro, conservarle la vida del mar al país, nosotros nos sustentamos pero la comunidad y el país también se sustenta” Pescador y Dirigente, 62 años.

En este sentido los pescadores artesanales son cuidadores naturales del mar, es por esto que en las negociaciones por la crisis de la merluza ellos proponían serias restricciones tanto ellos como para el sector industrial.

"Si queremos dejarle a las nuevas generaciones tenemos que perder nosotros y perder los industriales” Pescador, 70 años.

Los pescadores artesanales tienen comprometida su existencia en la sustentabilidad de los ecosistemas marinos. Para los accionistas de las empresas industriales el colapso de las pesquerías implica que el negocio dejará de ser rentable por lo que hay que diversificar la cartera de inversiones y buscar nuevas oportunidades de negocio, para los pescadores artesanales el mismo colapso implica el término de su forma de vida, de su cultura, del sustento de sus hijos y de la posibilidad de heredar su oficio.

"Vea usted quien está metido, el grupo Zaldívar, Angelini, son todos grandes capitales, ¿qué va a pasar con esos caballeros si se termina la pesca en Chile? (...) ellos pescan sus capitales y los ponen en otras partes” Pescador, 69 años.

A pesar de todo, los pescadores siguen luchando por mantenerse en tiempo y los dirigentes hablan con esperanza a futuro.

"Yo tengo la esperanza de que vamos a poder recuperar los recursos, al restringir las artes (...) yo creo que a un medio plazo, ni siquiera a largo plazo, podemos recuperar los recursos que pueda haber, más adelante, un futuro promisorio" Pescador y dirigente, 62 años.

\section{Reflexiones Finales}

La constitución de la identidad de la comunidad de pescadores artesanales se basa en la sanidad de los ecosistemas marinos y en el acceso 
que tengan a las distintas pesquerías. Históricamente se han conformado como un sujeto colectivo en torno a la productividad del mar, sus características y ciclos. Las historias familiares se han tejido en torno a este oficio, la colectividad existe como tal gracias a la pesca, la comunidad se articula en torno a ella. Los miembros de la comunidad de pescadores artesanales son los predadores superiores de una cadena trófica que actualmente se encuentra gravemente lastimada, y como tal, sienten las consecuencias de este daño.

Es por esto que los miembros de las comunidades de pescadores artesanales tienen un profundo interés en lograr la sustentabilidad del manejo pesquero, su forma de vida está en juego (lo que no quiere decir que este sector no tengan su cuota de responsabilidad en el deterioro de los ecosistemas marinos ya que sus desembarques también se han incrementado sostenidamente en el tiempo y hay pescadores artesanales que utilizan técnicas de pesca destructivas para el ecosistema marino como el arrastre artesanal, que actualmente se encuentra prohibido).

Las lógicas de la modernización no han sido son coherentes con los patrones culturales del sector artesanal y toda normativa que busque regular este sector debería considerar los aspectos culturales de este oficio además de las características productivas del mismo. La maximización de utilidades no es el objetivo fundamental del sector artesanal, más importante resulta la mantención de una forma de vida por algunos catalogada como "precapitalista” (Siches, 1998), la independencia laboral, la libertad de movimiento, la sociedad a la parte, el acceso colectivo, la confección de los aparejos de pesca, el trabajo artesanal, los vínculos familiares y comunitarios, la relación con "la mar", entre otros.

La definición legal de "pesca artesanal” no puede establecerse sólo como una actividad extractiva ya que incluye un fenómeno cultural y las “embarcaciones artesanales” no deberían definirse exclusivamente en términos del tamaño, actualmente, faenan en las 5 millas de preferencia artesanal embarcaciones que cumplen con los requisitos para ser consideradas artesanales (eslora máxima inferior a dieciocho metros y de hasta cincuenta toneladas de registro grueso), sin embargo, cuentan con avances tecnológicos y aparejos de pesca propios del sector industrial, y no forman parte de la estructura organizacional ni cultural de la pesca artesanal.

La versión de las cuotas individuales transferibles para el sector artesanal, los RAE, ha generado una fuerte resistencia por parte de muchas comunidades de pescadores artesanales porque violencia sus formas de organización y producción tradicional. Para ellos existen socios en un viaje de pesca, no patrones y empleados (Zamora, 2008). Atribuir las cuotas de pesca al armador (o sea al pescador que tiene un bote) implica privatizar el acceso a la pesca a favor de uno de los socios de la faena en desmedro del resto, por lo que genera una lógica jerárquica donde no la había (Glaría y Parraguez, 2009). 
Resulta indispensable realizar una revisión profunda del sistema de regulación pesquero vigente ya que éste no ha asegurado la sustentabilidad de la explotación de los ecosistemas marinos, importantísima fuente de recursos renovables en un país con más de 4000 kilómetros de costa. Existen diversos factores que articulan la actual tendencia a la insustentabilidad pesquera:

Por una parte, el que la Subsecretaría de Pesca (SUBPESCA) y Servicio Nacional de Pesca (SERNAPESCA) dependan del Ministerio de Economía incentiva una visión economista en la administración pesquera en la que se priorizan las ganancias de los actores económico relevantes por encima de los cuidados del medio ambiente y el respeto cultural hacia las comunidades locales. Desde la implementación de la actual institucionalidad y legalidad pesquera, luego del golpe militar, los desembarques se multiplicaron llegando a un punto de colapso en 1994 (División de Protección Pesquera, 1974-1976 y Servicio Nacional de Pesca 1979-2009). La implementación del modelo neoliberal que sustentó el éxito del crecimiento económico nacional y del modelo exportador tuvo profundas implicancias en la sanidad de los ecosistemas marinos, como lo muestran los relatos de quienes, desde siempre, han dependido del mar.

Por otra parte, los Límites Máximos de Captura por Armador no han asegurado la sustentabilidad de la explotación pesquera, en particular en el caso de la merluza común (cabe evaluar seriamente su efecto en otras pesquerías). La aplicación de esta medida de administración pesquera en la merluza común generó que se asignaran sistemáticamente cuotas mayores a los desembarques y superandon incluso el máximo histórico alcanzado por los desembarques de esta especie, cabe resaltar que la caída en las capturas producida a partir del 2002 era totalmente previsible dados los datos con que se contaba de las décadas de los 60 y 70. (Gráfico 1).

\section{Gráfico 1: Desembarques Totales, Industriales y Artesanales y las cuotas establecidas para la merluza común, 1940 - 2006.}

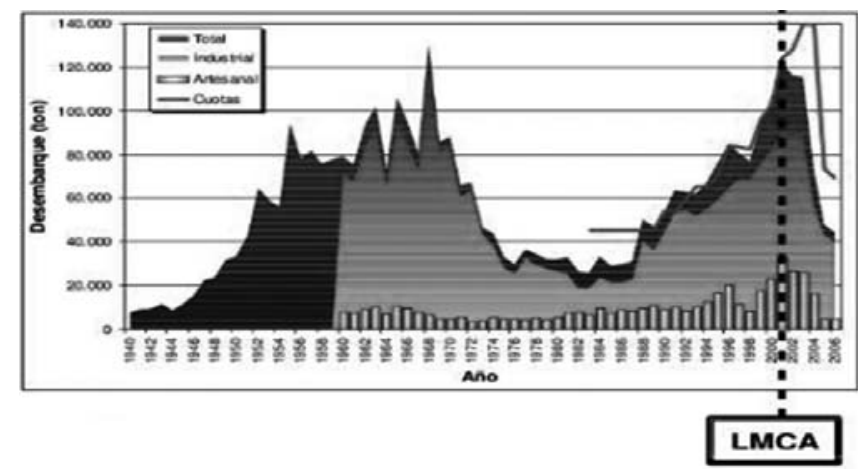

Fuente: Glaría y Parraguez (2009) con gráfico de SUBPESCA (2007) 
Con la aplicación de los LMCA se privatizó el acceso a la pesca en Chile. Las cuotas pesqueras ya no sólo tienen valor por la biomasa que representaban sino también valor de cambio por lo que, año tras año, se desencadenan fuertes presiones para mantener las cuotas elevadas. Quienes deciden las cuotas de pesca son los miembros del Consejo Nacional de Pesca, los que se benefician directamente de ellas, por lo que las cuotas asignadas tienden a sobrepasar los volúmenes sustentables de extracción, como se puede ver claramente en el caso de la merluza. "Es súper raro el Consejo Nacional, los mismos que pescan se asignan las cuotas” comentó uno de los funcionarios de la SUBPESCA (en: Glaría y Parraguez, 2009)

Finalmente cabe resaltar que muchas de las regulaciones impuestas legalmente quedan como letra muerta porque no existe la capacidad de fiscalización necesaria para controlar su correcta implementación. El descarte es una realidad de la cual escasean las cifras y sólo se puede especular su magnitud (por ende la importancia de sus impactos), debido a que no existen inspectores a bordo de los barcos. El subreporte (reportar menos de lo que se captura) es otra práctica habitual de la cual sólo se puede tener alguna idea en base a los casos detectados y las multas generadas. SERNAPESCA, único ente con potestad fiscalizadora en la actual institucionalidad, carece del personal y recursos necesarios para llevar plenamente a cabo su labor. "Se necesitarían al menos cuatro veces más personal para poder fiscalizar de forma efectiva todos los barcos que pescan" reconoce un miembro de SERNAPESCA (en: Glaría y Parraguez, 2009)

El próximo vencimiento de la ley corta impone con urgencia el debate acerca de la administración pesquera nacional y podría ser una oportunidad para abrir la discusión en torno a otros temas fundamentales como el status "res nullius" (territorio de nadie) de los recursos marinos vivos dado en la constitución del 80, el marco institucional dependiente del ministerio de economía, la distribución de las cuotas, los aparejos de pesca utilizados, el rol de las análisis científicos en la determinación de las cuotas, los criterios de sustentabilidad, la soberanía alimentaria, entre otros.

En cuanto a las decisiones concretas a tomar por el término de esta legalidad queda por resolver si se extenderá el uso de los LMCA, los RAE, el porcentaje con el que se distribuirán las cuotas de pesca y su mecanismo, si se hará por criterios histórico, como se ha hecho hasta el momento, o por subasta, con lo que el Estado obtendrían ingresos por autorizar la explotación de los recursos marinos en aguas nacionales que podrían ser destinados a programas de conservación, investigación, fiscalización, reservas marinas, ayudas al sector artesanal, entre muchas otras muchas acciones que podrían resultar pertinentes en la actual situación de daño ecosistémico.

En este escenario las comunidades de pescadores artesanales se vuelven actores esenciales en la búsqueda de sustentabilidad, porque ellos requieren, para continuar existiendo, de un manejo adecuado de la actividad pesquera. Con esto no quiero decir que no haya contradicciones, distintas 
posturas e incluso conflictos de interés dentro del sector artesanal, quiero decir que ellos necesitan inexorablemente de la sanidad de los ecosistemas marinos si pretende seguir existiendo como cultura y forma de sustento.

Se podría pensar que esta lógica también es aplicable al sector industrial, ya que, al igual que el sector artesanal, sin pesca no pueden continuar trabajando. Sin embargo, los criterios economicistas de maximización de utilidades en beneficio de los accionistas de las empresas tienden a desacoplar al sector industrial de la búsqueda real de sustentabilidad y los límites que ésta impone, por ejemplo, si el costo de oportunidad de la actividad económica alternativa más rentables del mercado es muy alto, es decir, la tasa de descuento es muy elevada, la extinción de una especie puede ser considerada un punto óptimo en el sentido económico (Erickson, 2000).

Urge diseñar una legalidad que asegure que los niveles de captura se mantengan por debajo de la tasa de regeneración de cada especie y regular los aparejos de pesca de modo que generen el menor daño ecosistémico posible. Los miembros de las comunidades de pescadores artesanales deberían tener un rol fundamental en esta búsqueda de sustentabilidad pesquera y la sociedad civil debería apoyarlos para que así sea, ya que, tanto ellos como nosotros/as, ciudadano/as de este país eminentemente costero, requerimos de la sanidad de los ecosistemas marinos para poder creer en la promesa de "un futuro esplendor".

"Mi vida toda ha sido la mar, toda la vida"

Pescador, 80 años. 


\section{Notas}

* Se le agradece a Pablo Parraguez el apoyo en la realización del trabajo de campo que se cita en el presente artículo y la discusión de algunas de las ideas aquí planteadas.

${ }^{1}$ Citado en Jofré González, José. (2001) “Economía de los recursos pesqueros”, Universidad de Chile, Facultad de ciencia económicas y administrativas. Bravo y Allende Editores.

${ }^{2}$ Esas cifras no incluyen la pesca no declarada o descartada que realmente un porcentaje importante de la captura en numerosas pesquerías

${ }^{3}$ Individual Transferable Quota

${ }^{4} 22$ Mayo, 1984, La Nación, Pág. 4 columna 2, Biblioteca del Congreso

${ }^{5}$ Ley que prorrogó la ley $N^{\circ} 19.713$

${ }^{6}$ Las citas de los miembros de la comunidad de pescadores artesanales provienen del trabajo de campo de la investigación de Glaría, V. y Parraguez, P. (2009) “Tranformaciones de las Interaccion Socioeconómicas de la pesca artesanasal de la caleta El Membrillo en la útlimas cuatro décadas: crónica de una crisis anunciada” Memoria de la Carrera de Socecioeconomía, Universidad de Valparaíso. Algunas de las estas citas se encuentran publicadas en este trabajo de memoria y otras provienen directamente de las trascripciones de las entrevistas. El trabajo de campo se desarrolló entre Marzo del 2008 y Noviembre del mismo año y se realizaron entrevistas en profundidad a 12 miembros del sindicato de la caleta El Membrillo (pescadores, buzos y encarnadoras), su utilizó la observación directa del trabajo de la caleta y se realizaron entrevistas semi estructuradas a informantes expertos de contextos, miembros de SERNAPESCA, SUBPESCA, IFOP, CONAPACH, entre otros. 


\section{Bibliografía}

Ben-Yami, M. (2003), “Secuestradas por el Neoliberalismo” Revista: Reporte Sumadra $n^{\circ} 35$, Julio. Chennai, India.

Coase, R. (1960), "El problema del coste social”. Revista: The Journal of Law and Economic, Octubre, páginas 1-44. Chennai, India.

Copes, P. (1999), “¿Para quién son los recursos costeros?”, Revista: Reporte Samudra $n^{\circ} 23$, Septiembre.

CONAPACH, (Confederación Nacional de Pesca Artesanal) (2006), Estudio de caso: acceso a los recursos pesqueros en Chiles, Editado por CONAPACH.

Ídem (2007), “Crisis de la Merluza Común” Presentación a la Sesión Comisión de Intereses marítimos, pesca y acuicultura del Senado de Chile. 27 agosto Congreso Nacional.

Cruz, J. y Argüello, F. (2006), "Paradigmas de la Antropología en el Estudio de las Sociedades Costeras”. Revista: Mad número 15, Septiembre, Departamento de Antropología. Universidad de Chile.

Dirección de Pesca y Caza, Ministerio de agricultura (1944-1973), Información estadística, Editado por el Ministerio de Agricultura, Santiago, Chile.

División de Protección Pesquera, Miniterio de Agricultura (1974-1976), Anuarios Estadísticos de Pesca, Editado por el Ministerio de Agricultura, Santiago, Chile.

Erickson, Jon (2000), “Endangering the economics of extinction”, Revista: Wildlife Society Bulletin 28(1):34-41, EEUU.

FAO (2009), El estado mundial de la pesca y la acuicultura, 2008, Departamento de Pesca y Acuicultura de la FAO, Roma.

Ídem (2000), “Taller sobre manejo y asignación de recursos pesqueros a pescadores artesanales en América latina”, 25 - 26 abril del 2000, Valparaíso, Chile.

Glaría, V. y Parraguez, P. (2009), Tranformaciones de las Interaccion Socioeconómicas de la pesca artesanasal de la caleta El Membrillo en la útlimas cuatro décadas: crónica de una crisis anunciada, Memoria Carrera de Socecioeconomía Universidad de Valparaíso, Valparaíso, Chile.

Hardin, G. (1968), “The tragedy of the comons” Revista Science Vol. 162. no. 3859, pp. $1243-1248$. 
Jofré González, José. (2001), Economía de los recursos pesqueros, Universidad de Chile, Facultad de ciencia económicas y administrativas. Bravo y Allende Editores, Santiago, Chile.

La Nación, 22 Mayo de 1984, Pág. 4 columna 2, Santiago, Chile.

Ley de Pesca No 18.892 y sus modificaciones: Ley General de Pesca y Acuicultura. Valparaíso, 28 de Septiembre de 1991.

Quiroga, R. y Van Hauwermeiren, S. (1994), Globalización e insustentabilidad. Una Mirada desde la economía ecológica, Editado por el Instituto de Ecología Política, Santiago, Chile.

Siches, C. (1998), Los pescadores de la isleta del Moro, Volumen 3 Estudios de antropología social y cultural, Editado por Universidad de Barcelona, Barcelona.

Servicio Nacional de Pesca, SERNAPESCA, Ministerio de Economía Fomento y reconstrucción (1979-2009), Anuarios estadísticos de pesca, Editado por el Ministerio de Economonía Fomento y Reconstrucción, Santiago, Chile.

Subsecretaría de Pesca, SUBPESCA (2007), Política Nacional Pesquera, Editado por el Ministerio de Economía Fomento y Reconstrucción, Santiago, Chile.

Subsecretaría de Pesca, SUBPESCA (2007), Noviembre, Informe técnico número 97: Cuota Global Anual Captura Merluza Común, año 2008, Editado por el Ministerio de Economía Fomento y Reconstrucción, Santiago, Chile.

Yu Chang, M. (2005), “Economía Ambiental”, Capítulo 6 de: Foladori, G. y Pierre, N. ¿Sustentabilidad? Desacuerdos sobre el desarrollo sustentable, 2005.

Zamora, Antonio J. (2008), Descripción del subsistema económico llamado "sociedad a la parte" entre los pescadores artesanales del litoral de Valparaíso y su relación con la crisis económico ambiental sucedida por la merma de la merluza común, Tesis Escuela de Antropología Social, Universidad Bolivariana.

Recibido: 15.10 .2010

Aceptado: 17.11.2010 